\title{
Der Anfang neuer Traditionen
}

_ Der Jahreswechsel ist die Zeit für Neubeginn. Die erste Neuerung gibt's direkt in diesem Heft, denn wir stellen uns für Sie auf den Kopf. Ab sofort erhalten Sie den praxisprofi 8- statt 4-mal im Jahr - ein echter Mehrwert also für Sie als unsere treuen Abonnenten. Drehen Sie die ergopraxis einfach um und schmökern Sie nahtlos im praxisprofi weiter.

_ Ein erster Blick in unsere Leserumfrage hat uns darin bestärkt, dass unsere Ideen mit Ihren Wünschen übereinstimmen und wir den Anfang neuer Traditionen wagen können!

_ Auch der ergotag hält eine Neuerung für Sie bereit: Wir ziehen mit unserer Veranstaltung um zur MEDIZIN Messe Stuttgart und ändern damit nicht nur den Ort, sondern auch das Veranstaltungsdatum auf Januar. Es freut uns sehr, dass der ergotag ein neues Zuhause bekommt und unsere Teilnehmer mit der TheraPro eine größere Ausstellung besuchen können als bisher. Der 7. ergotag zum Thema Infantile Zerebralparese findet statt am 27.1.2013. Weitere Informationen erhalten Sie im Programmheft, das dieser Ausgabe beiliegt.

Ich wünsche Ihnen ein glückliches und gesundes neues Jahr 2013! Ihre

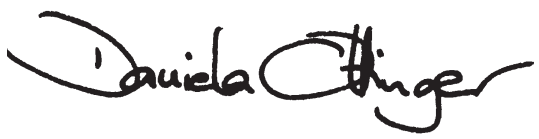

\section{ZU GEWINNEN}

Kursplatz

1 Kurs „Handwriting without Tears“"

Seite 43

Bücher

2-mal „F.O.T.T.“

Seite 19

3-mal "Ich bin besonders“ Seite 20 2-mal „Neuroreha nach Schlaganfall“"

Seite 30

Und außerdem...

6 Massagehandschuhe Seite 30 1 Janosch Wärmestofftier Seite 42 